\title{
correspondence
}

\section{Israeli participation in Soviet conference}

SIR,--It was with great disappointment that I read the letter (16 February, page 605) on Soviet 'discrimination' against Israeli scientists in connection with the International Meeting on Ferroelectricity held in Leningrad 18-23 September, 1977. I was one of the vice-chairmen on the conference organising committee. In this capacity and on the instruction of the organising committee, I assisted in arranging for Israeli scientists to participate in the conference.

In particular, I spoke twice to Dr W. Merz of RCA Zurich in July and informed him that the Israeli scientists' papers had been accepted and that visas would be issued. Later on in mid-August, on the request of the organising committee, I called Dr Merz from my laboratory in Moscow and consulted him on the best place from which to issue the visas to the Israeli scientists.

At the time four names were mentioned to me; unfortunately I can now only recall that of $\mathrm{Mr} \mathrm{S}$. Havlin. Dr Merz and I agreed that visas for two participants (Mr Havlin was one of them) would be issued at the Soviet Embassy in Rome. The other two would be issued in Vienna. I asked Dr Merz to inform the Israeli participants accordingly and was quite sure that the matter was settled.

Nevertheless, when I returned to Vienna on 12 September, I checked on whether or not the visas had been issued by the Soviet Embassy, and I was astonished to find that the Embassy had received no applications for visas from Israel. I now understand that the Soviet Embassy in Rome received no visa request either. Last November, I contacted Dr Shuvalov in Moscow to clarify some details of the arrangements made for the Israeli scientists. I understood from him that the organising committee was not informed that Mr Havlin had applied for his visa in Paris and not in Rome, until the beginning of September. Action had been taken immediately and on 9 September the Soviet Embassy in Paris was instructed to issue the visa.

It is regrettable that Israeli scientists were not able to participate in the International Meeting on Ferroelectricity. It is regrettable that through no fault of ours but because of understandable difficulties in communication between Israel and the Soviet Union details of arrangements for conference participation were delayed. Considering the problem of Israeli participation in the conference, one has to take into account in addition the fact that for purely technical reasons the distribution of the information circular was delayed to all participants.

I find the last part of the letter completely inappropriate. Rather than avoiding difficulties in future, it would be more likely to create new ones. The recommendations to impose certain conditions when arranging international conferences in the Soviet Union are based on a personal understanding of a few international problems and neglect the tremendous international advantages in cooperation between West and East. On the basis of the experience gained through the Leningrad conference, the organising committee could, but never would, come to some completely opposite conclusions. For example, we could judge the fact that just two scientists tried to participate instead of the four we were informed of, as an additional difficulty created

intentionally. Further, the appeal in the letter to impose all those restrictions before the matter is clarified could be converted-but will not be-to an appeal to the relevant scientific community not to invite Israeli scientists to international conferences until the writers apologise for the distribution of improper information.

\section{Moscow, USSR}

\section{S. Z Zeludev}

\section{IQ and environmental variables}

SIR,- - Stephen Gould is quoted (23 February, page 699) as saying that Arthur Jensen's work rests on "a fundamental fallacy", namely, that he fails to understand that an average difference between populations in IQ need not be genetic "even if the IQ is heritable within the black and white populations". The scientific assertion is correct, but it is incorrect to attribute this reasoning to Jensen.

What Jensen does argue is that there is a significant connection between 'within group' and 'without group' heritability such that high within group heritability lessens the probability of environmental explanations for a difference between groups. And he is right. We can see why this is so simply by imagining the environment as made up of a large number of elemental factor variations which may or may not affect IQ, and then rephrasing the question as follows: would any of these factors be excluded as a cause of an average difference between groups if the within group heritability were (say, for expository purposes) 1.0 ? The answer is yes: namely, that class of environmental factors where the difference (if any)

\section{Sorry, for copyright reasons some images on this page may not be available online}

between the two groups is within the range of variation already sampled in the group in which a heritability of 1.0 was determined.

We can illuminate this by developing the example cited by Nature: assume two groups, $A$ and $B$, differing in average height, and let us ask if dietary factors could account for this difference. If whatever group difference that existed in the diets of A and B were within the range of diet variation already examined in determining the heritability of height in A, then a heritability of 1.0 in A certainly would exclude that diet difference as a cause of the group difference in height. If on the other hand the heritability were zero (and especially if this were a result of diet variation in $\mathrm{A}$ ), then any significant difference in diet between $A$ and $B$ would be a plausible cause of the height inequality.

Thus, by excluding a sizable class of environmental variables, high within group heritability unarguably does raise the probability of the remaining classes of possible explanations, of which there are two: either a gentic difference, or else an environmental difference between groups that is not represented within groups (and hence was not sampled in the determination of within group heritability). Since it happens that many of the environmental correlates of racialism have precisely this kind of distribution (segregated schooling, psychological injuries associated with being a minority, and many more), this latter class is by no means an empty formalism. Nevertheless, whether some member of this rather than the genetic category is the cause of the group IQ difference needs demonstrating, not merely hypothesising. It is in evaluating the relative likelihood of these two formal possibilities that an assessment of programmes like Head Start (that explicitly predicated an environmental deficit as the origin of individual and group differences in IQ) becomes relevant. And it is primarily the unimpressive success of this and many similar "environmentalist" prescriptions that led Jensen to prefer a genetic explanation.

That is, it is not, pace Mr Gould, an elementary misunderstanding of heritability theory at all that is the fons vitae of Jensen's position but rather the consideration over and above theory of a vast body of empirical evidence. Thus those among us who would dispute Jensen cannot confine their criticism merely to abstract theorising; what is needed to 'falsify' the genetic interpretation once and for all, and simultaneously to provide the clue that could lead to sound and compassionate social policy, is the empirical demonstration of at least one extant environmental difference between racial groups that, when equalised, significantly reduces the IQ difference. Until this can be done, the 'environmentalist' interpretation is unlikely to contribute much of a concrete nature to the shaping of wise social policy.

Berkeley, California, USA 